\title{
Analysis on the Durability of Hybrid Polymer Composites for Power FGD System
}

\author{
Zhenyu Wang1, Lijie Xiu², Enhou Han', Yunhe Zhang3, Yongan Zhao², Ming Liu² \\ ${ }^{1}$ National Engineering Research Centre for Corrosion Control of Metals, Institute of Metal Research, Chinese \\ Academy of Sciences, Shenyang, China \\ ${ }^{2}$ Ningxia Jingneng Ningdong Electric Power Generation Co., Ltd., Yinchuan, China \\ ${ }^{3}$ Gude Anti-Corrosion Engineering Co., Ltd., Dalian, China \\ Email: zzyywang@imr.ac.cn
}

Received 3 January 2016; accepted 8 March 2016; published 11 March 2016

Copyright (C) 2016 by authors and Scientific Research Publishing Inc.

This work is licensed under the Creative Commons Attribution International License (CC BY).

http://creativecommons.org/licenses/by/4.0/

c) (i) Open Access

\begin{abstract}
The corrosion condition of flue gas desulfurization (FGD) equipment for the coal-fired power plant was defined as the strong corrosion grade. The lining system of hybrid polymer composite was used in internal cylinder of steel chimney, and a corrosion-resistant and heat-resistant protective layer was formed on the metal surface. The corrosion-resistant and ageing-resistant properties of hybrid polymer composite prepared at low temperature after four years of practical use were investigated by differential scanning calorimeter (DSC), scanning electron microscopy (SEM) and measurement of gravimetric variation, contact angle, abrasion resistance, bonding strength and tensile strength. The properties of hybrid polymer composites prepared at $25^{\circ} \mathrm{C}$ and $-15^{\circ} \mathrm{C}$ were comparatively analyzed in the paper.
\end{abstract}

\section{Keywords}

Coal-Fired Power Plant, Flue Gas Desulfurization, Hybrid Polymer Composite, Durability, Corrosion Resistance

\section{Introduction}

FGD system has been widely used to remove sulfur dioxide from flue gases of power plants. Some corrosive ions, such as $\mathrm{SO}_{4}^{2-}, \mathrm{SO}_{3}^{2-}, \mathrm{NO}_{\mathrm{x}}^{-}$and $\mathrm{Cl}^{-}$, exist in the saturated wet flue gases after desulfurization. Dew point corrosion of sulfuric acid, wet/dry alternation, thermal stress and wear of flue gas all contribute to the aggressive damage of desulfurization equipment. Titanium steel plate, cellular glass boards, organic coatings, glass fiber reinforced plastics and inorganic-organic hybrid polymer composites have been applied in corrosion pre- 
vention of wet desulphurization chimney. Organic-inorganic hybrid composite has recently been developed from the concept of intermingling on a nanometer scale domain of organic and inorganic components, and a "hybrid" character between the two components was obtained in the resulting material. The inorganic-organic hybrid composite as a high-performance anti-corrosion material combines the chemical and physical properties of both inorganic and organic components, and has shown the excellent mechanic strength, bonding strength, strain resistance and corrosion protection. Therefore, the hybrid polymer composite can successfully be proposed as a protective material for steel [1]-[7].

The hybrid polymer composite (silicon-contained heterocyclic polymer with enhanced fibers) has been applied in the lining of desulfurization chimney in Ningdong electric power plant for four years and four months. The comparative studies in the paper are in progress to evaluate the efficiency of the hybrid polymer composites for protecting the metal substrates. The properties of the hybrid polymer composites prepared at $25^{\circ} \mathrm{C}$ and $-15^{\circ} \mathrm{C}$ are compared with those of composites after long time of practical use, and are assessed by differential scanning calorimeter, scanning electron microscopy and measurement of contact angle, gravimetric variation, abrasion resistance, bonding strength and tensile strength [8]-[12].

\section{Materials and Methods}

\subsection{Materials and Sample Preparation}

The hybrid polymer composite formed a chimney lining from the reaction of silicon-contained heterocyclic polymer (Gude Co.) with the sulfone-containing amine curing agent. The hybrid composite samples with size of 20 $\mathrm{mm} \times 10 \mathrm{~mm} \times 3 \mathrm{~mm}$ were gained from field sampling after four years and four months of use. A group of samples with thickness of $3 \mathrm{~mm}$ were prepared at $25^{\circ} \mathrm{C}$, while other group of samples with same thickness were firstly prepared at $-15^{\circ} \mathrm{C}$ for $120 \mathrm{~h}$ and then placed at $25^{\circ} \mathrm{C}$ for $48 \mathrm{~h}$. Because hybrid polymer composites often were prepared on the spot in the summer or winter, these two temperatures $\left(25^{\circ} \mathrm{C}\right.$ and $\left.-15^{\circ} \mathrm{C}\right)$ were chosen.

\subsection{Acid Immersion Test}

The accelerated corrosion test was operated in the mixed acid at $50^{\circ} \mathrm{C}$ for 1000 hours, and the mixed acid contained $5 \% \mathrm{H}_{2} \mathrm{SO}_{4}, 1 \% \mathrm{HCl}, 0.5 \% \mathrm{HNO}_{3}$ and $0.3 \% \mathrm{HF}$. The test was used to evaluate the corrosion resistance of the hybrid polymer composite using the gravimetric method. The acid absorption was calculated by weight gain of the specimens immersed in acid solution, and weight gain of samples was plotted as a function of immersion time.

\subsection{Analysis Methods}

DSC measurements were determined by a Perkin-Elmer differential scanning calorimeter using a temperature scan from $25^{\circ} \mathrm{C}$ to $100^{\circ} \mathrm{C}$ with a heating rate of $10^{\circ} \mathrm{C} / \mathrm{min}$. A XL30 ESEM instrument operated at $20 \mathrm{kV}$ was used to observe the SEM micrographs of hybrid composite samples after practical application. The contact angles of hybrid polymer composites were measured by JC2000D2 instrument, and the multiple measurements were necessary to reflect variation in treatment and surface roughness. The tensile strengths of the samples were measured at a tension speed of $5 \mathrm{~mm} / \mathrm{min}$ according to GB/T1040.2-2006 standard, and the average values of tensile strengths of three same samples were recorded. Measurement of adhesion strengths was performed according to ASTM C633-01 standard. Two steel sticks stuck together with hybrid polymer composites were continually drawn by using a drawing machine until two steel sticks were divided, and the values of divided force were recorded as the adhesion strengths. The abrasion resistance of hybrid polymer composites was measured by GB/T5478-2008 standard. Grit size of the abrasion test is $100 \#$, and speed and load is $70 \mathrm{rpm}$ and $1000 \mathrm{~g}$, respectively.

\section{Results and Discussions}

\subsection{SEM Observation}

SEM morphologies of hybrid polymer composite after four years of practical use are shown in Figure 1. If polymers are degraded or damaged after long time of application, some defects will appear on the surface of hybrid polymer composite. From the observation of SEM micrographs, no separate second phases or eroded cracks can 


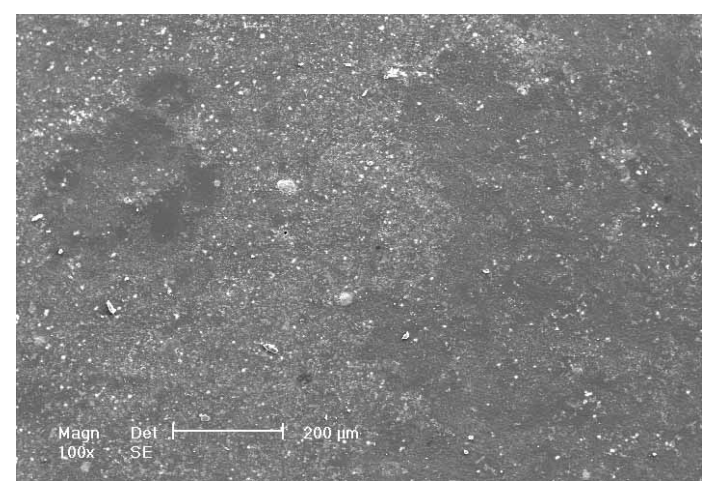

(a)

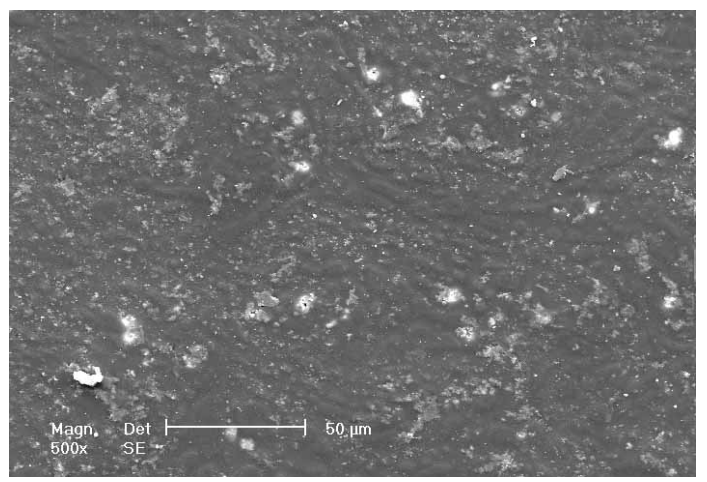

(b)

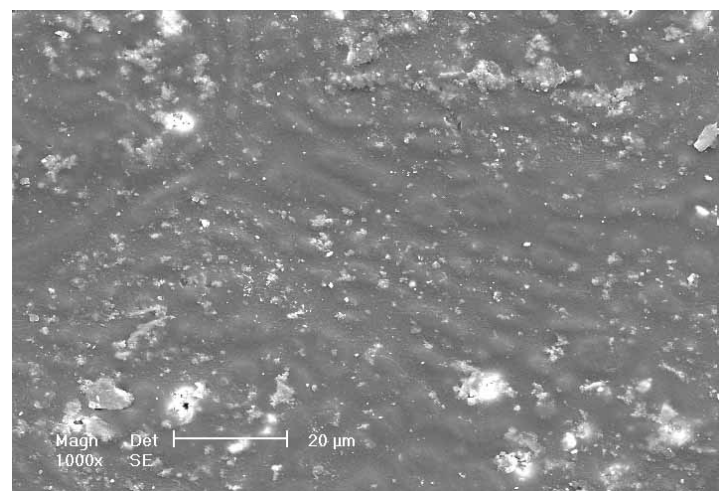

(c)

Figure 1. SEM morphologies of hybrid polymer composites after four years of use: (a) $100 \times$, (b) $500 \times$ and (c) $1000 \times$.

be found on the polymer surface. This indicates that cross-linking network of hybrid polymer composite is not destroyed when exposed to the corrosive condition of desulfurization chimney [13] [14].

\subsection{DSC Analysis}

DSC analysis is used to determine glass transition temperature $\left(T_{\mathrm{g}}\right)$ of polymer network. Because too many variables affect the $T_{g}$, the DSC analysis of $T_{g}$ is only used as a reference evaluation in the paper. The glass transition of polymer is a change in the heat capacity when the polymer matrix goes from the glass state to the rubber state. The thermal stability of hybrid polymer composite before and after practical use is evaluated by DSC analysis of Figure 2. $\mathrm{T}_{\mathrm{g}}$ of hybrid polymer composite prepared at $25^{\circ} \mathrm{C}$ before practical use is $226.2^{\circ} \mathrm{C}$, and $\mathrm{T}_{\mathrm{g}}$ of hybrid polymer composite prepared at $-15^{\circ} \mathrm{C}$ after four years of practical use is $217.5^{\circ} \mathrm{C}$. $\mathrm{T}_{\mathrm{g}}$ of hybrid polymer composite only decreases $8.7^{\circ} \mathrm{C}$ after the practical use. This demonstrates that the hybrid polymer composite can resist corrosion damage and thermal degradation when exposed to the desulfurization environment [15] [16].

\subsection{Analysis of Penetration Resistance}

The hybrid polymer composites are exposed to acid solution for 1000 hours, and the permeation resistance is determined by weight evolution. As shown in Figure 3, different exposure times are associated with the different stages of weight evolution for the composites. Hybrid polymer composites provide the corrosion protection for metal substrate, and their barrier properties before and after practical use are investigated by gravimetric measurement. When the hybrid polymer composites are exposed to corrosive media, they gain rapidly in weight at the initial stage and increase to the maximum weight between 168 hours and 216 hours. The maximum weight gain of hybrid polymer composite prepared at $25^{\circ} \mathrm{C}$ is $1.2 \%$, and that of composite prepared at $-15^{\circ} \mathrm{C}$ before use is $1.3 \%$. This result demonstrates that the effect of initial preparation temperature on the corrosion resistance of hybrid polymer composite is very small if normal application temperature is above $25^{\circ} \mathrm{C}$. Compared with $1.2 \%$ 


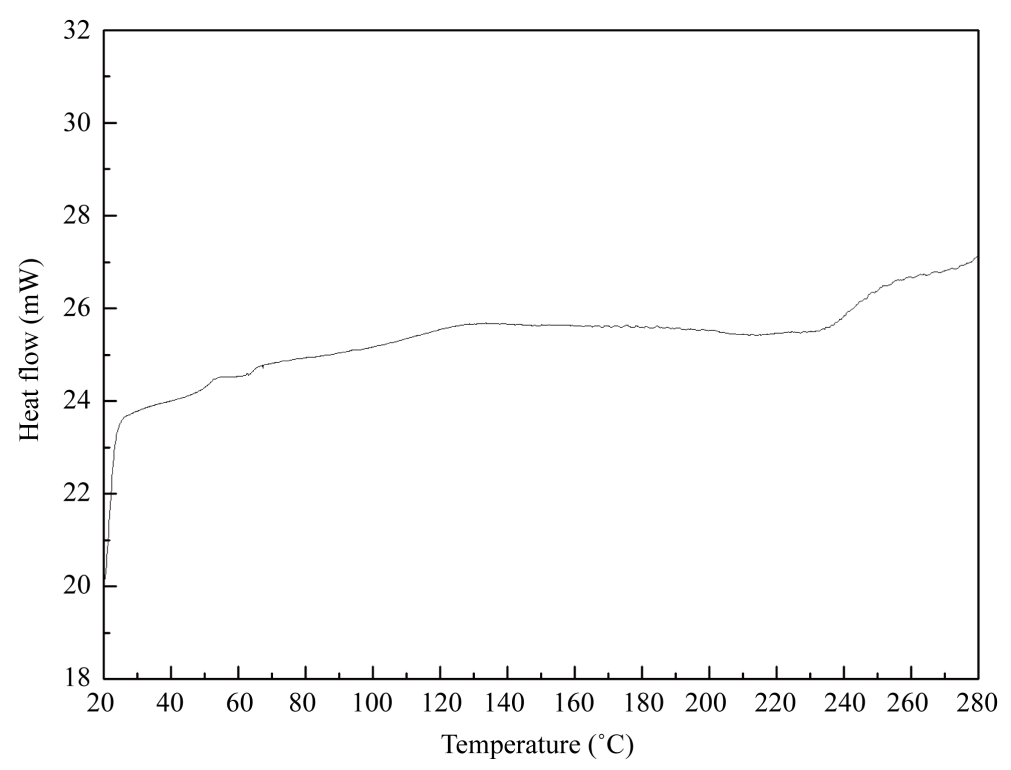

(a)

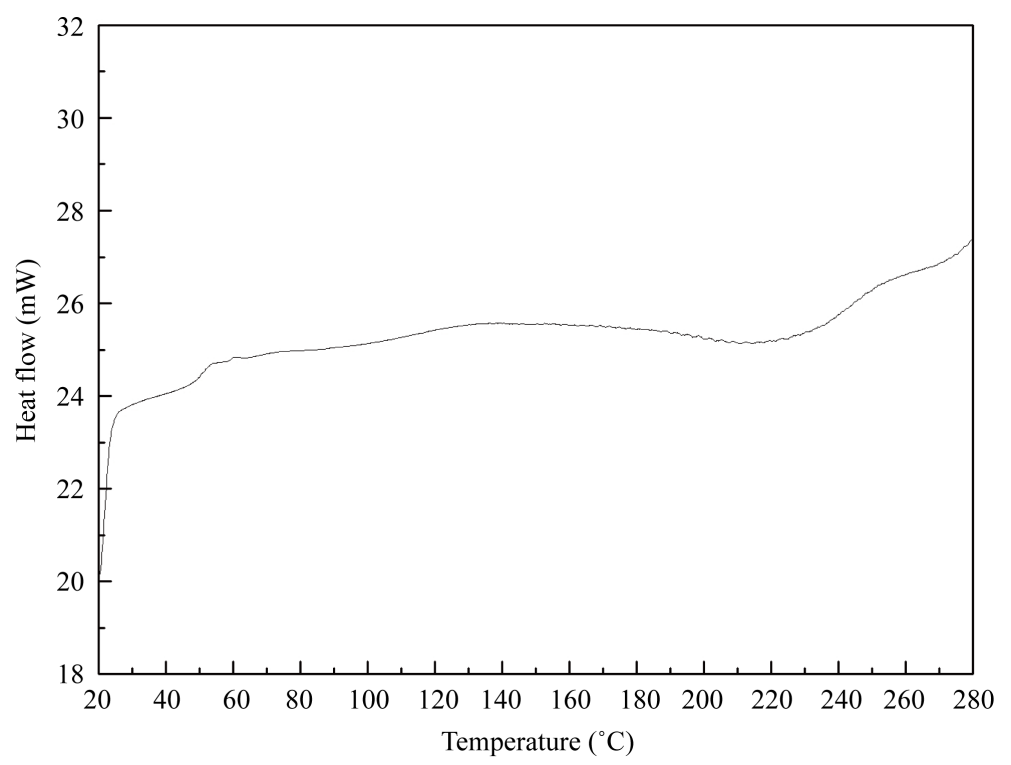

(b)

Figure 2. (a) DSC curves of hybrid polymer composite prepared at $25^{\circ} \mathrm{C}$ before practical use; (b) DSC curves of hybrid polymer composite prepared at $-15^{\circ} \mathrm{C}$ after four years of practical use.

of hybrid polymer composite prepared at $25^{\circ} \mathrm{C}$ before the practical use, the maximum weight gain of hybrid composite after four years of use is $1.9 \%$. The weight gain of hybrid polymer composite before and after practical use changes very little at the stage of 168 - $1000 \mathrm{~h}$, which indicates that the permeability of corrosive media and dissolution of small molecules reached a balance. The mixed acid with $\mathrm{SO}_{4}^{2-}, \mathrm{Cl}^{-}, \mathrm{NO}_{3}^{-}$and $\mathrm{F}^{-}$at $50^{\circ} \mathrm{C}$ cannot destroy molecular bonds of hybrid polymer, and the corrosive media are very difficult to enter polymer network. The result reveals that the corrosion resistance of hybrid polymer composite is very strong even after four years of use [17]-[20].

\subsection{Analysis of Contact Angles}

Figure 4 illustrates the variation of contact angles with time in the accelerated corrosion test for hybrid polymer 


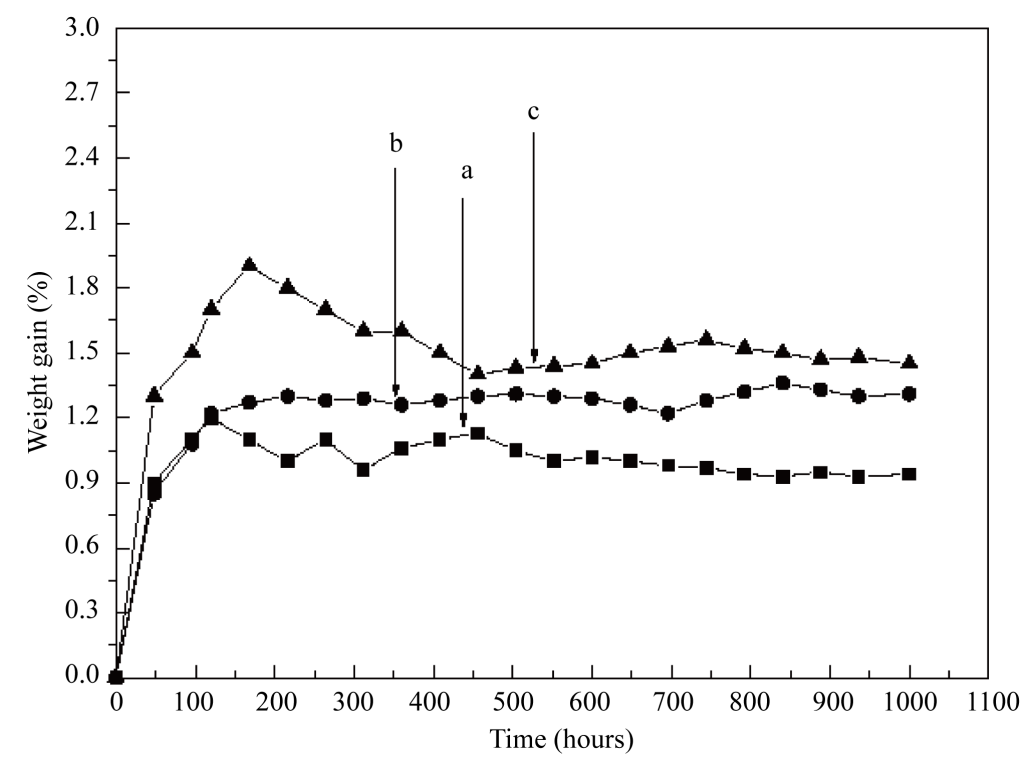

Figure 3. Weight change evolution with time in the accelerated acid corrosion test for hybrid polymer composite prepared at $25^{\circ} \mathrm{C}$ before practical use (a), prepared at $-15^{\circ} \mathrm{C}$ before practical use (b) and after four years of use (c).

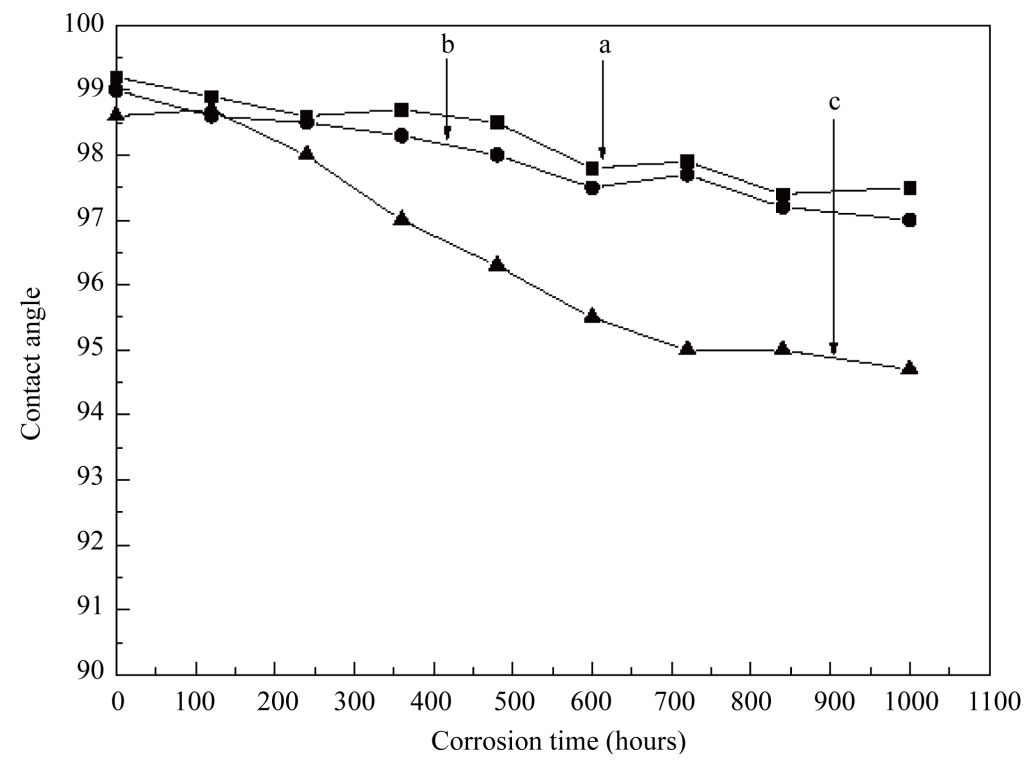

Figure 4. Evolution of contact angles with time in the accelerated acid corrosion test for hybrid polymer composite prepared at $25^{\circ} \mathrm{C}$ before practical use (a), prepared at $-15^{\circ} \mathrm{C}$ before practical use (b) and after four years of use (c).

composites. The contact angle of hybrid polymer composites prepared at $25^{\circ} \mathrm{C}$ and $-15^{\circ} \mathrm{C}$ is $99.2^{\circ}$ and $99.0^{\circ}$, respectively. The contact angle of hybrid polymer composite after the four years of use decreases from $99.0^{\circ}$ of hybrid composite before use to $98.6^{\circ}$. It is illustrated that low preparation temperature and practical corrosion condition don't decrease dramatically the contact angles of hybrid polymer composite. After 1000 hours of accelerated acid corrosion test, the contact angle of hybrid composites prepared at $25^{\circ} \mathrm{C}$ and $-15^{\circ} \mathrm{C}$ is $97.5^{\circ}$ and $97.0^{\circ}$, respectively, while the contact angle of hybrid composites after four years of use is $94.7^{\circ}$ that is only $2.3^{\circ}$ lower than that of hybrid composites before use. This demonstrates that hybrid polymer composites can retain the low surface energy even after four years of use and 1000 hours of accelerated corrosion test. Therefore, the hybrid polymer composites can provide the excellent resistance to pollution and aging when they are applied in 
wet desulphurization condition [21]-[24].

\subsection{Analysis of Bonding Strength}

The variation curves of bonding strengths with immersion time for hybrid polymer composites are shown in Figure 5. The bonding strengths of hybrid polymer composites prepared at $25^{\circ} \mathrm{C}$ and $-15^{\circ} \mathrm{C}$ is 12.1 and 11.7 $\mathrm{MPa}$, respectively. After the acid corrosion test of $1000 \mathrm{~h}$, the bonding strength of hybrid composite prepared at $25^{\circ} \mathrm{C}$ decreases from 12.1 MPa of hybrid composite before the immersion test to $11.0 \mathrm{MPa}$, and the bonding strength of hybrid composite prepared at $-15^{\circ} \mathrm{C}$ decreases relatively from $11.7 \mathrm{MPa}$ before the immersion test to 9.0 MPa after. It can be inferred that low preparation temperature has a negative effect on the bonding strengths of hybrid composites after a long time of acid corrosion test [25] [26].

\subsection{Analysis of Tensile Strength}

The mechanical properties of hybrid polymer composites will be damaged if their molecular structures are degraded in the process of material application. Variation curves of tensile strengths of composites as a function of immersion time are shown in Figure 6.

The tensile strength of hybrid polymer composites after four years of use decreases from 65.2 MPa of hybrid composite before use to 62.1 MPa. Only a small change of 3.1 MPa in tensile strength demonstrates that hybrid polymer composites retain the excellent mechanical properties after a long time of application in desulphurization environment. The accelerated corrosion test is used to study comparatively the mechanical properties of hybrid polymer composite prepared at different temperature when used in corrosive condition. After the accelerated corrosion test of 1000 hours, the tensile strength of hybrid polymer composites before and after practical use is $62.5 \mathrm{MPa}$ and 59.0 MPa, respectively. Therefore, the corrosive desulphurization environment and accelerated corrosion test cannot seriously damage the mechanical properties of hybrid polymer composites [27] [28].

\section{Conclusion}

From the SEM observation, no defects are found on the surface of hybrid composites after exposure of four years to the FGD corrosive environment. DSC analysis demonstrates that $\mathrm{T}_{\mathrm{g}}$ of hybrid polymer composite only decreases $8.7^{\circ} \mathrm{C}$ after the practical use of four years. As shown by the accelerated acid corrosion test, a small weight change of hybrid polymer composites before and after practical use indicates that the corrosion resistance

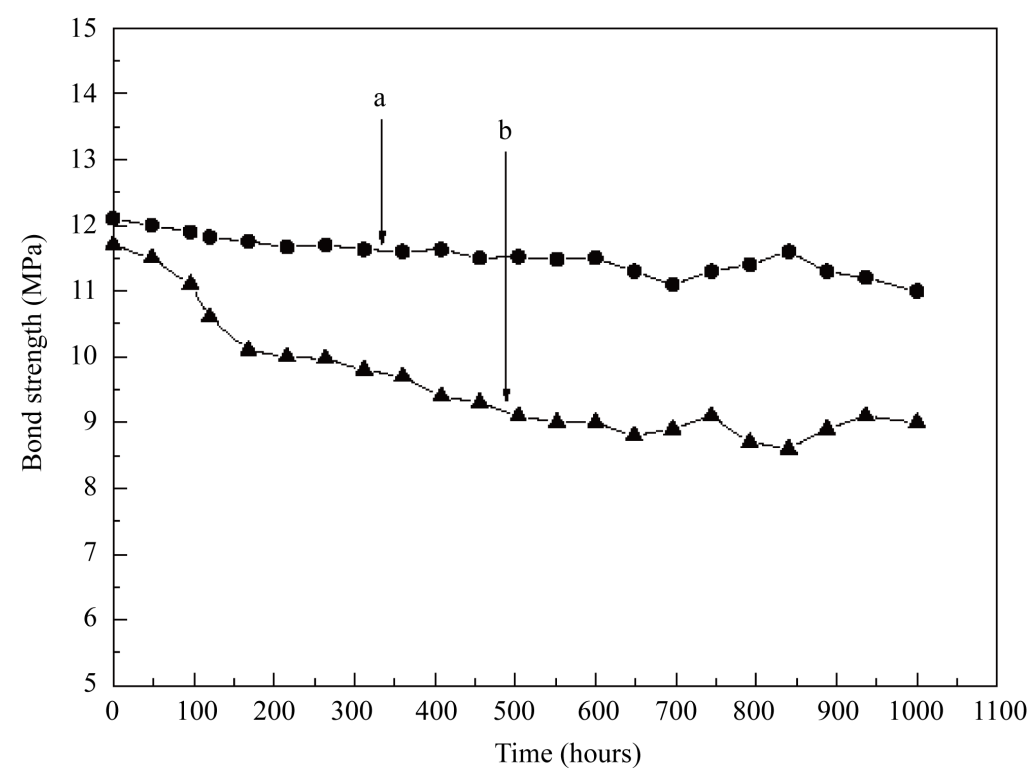

Figure 5. Evolution of bonding strengths with time in the accelerated acid corrosion test for hybrid polymer composite prepared at $25^{\circ} \mathrm{C}$ before practical use (a) and prepared at $-15^{\circ} \mathrm{C}$ before practical use (b). 


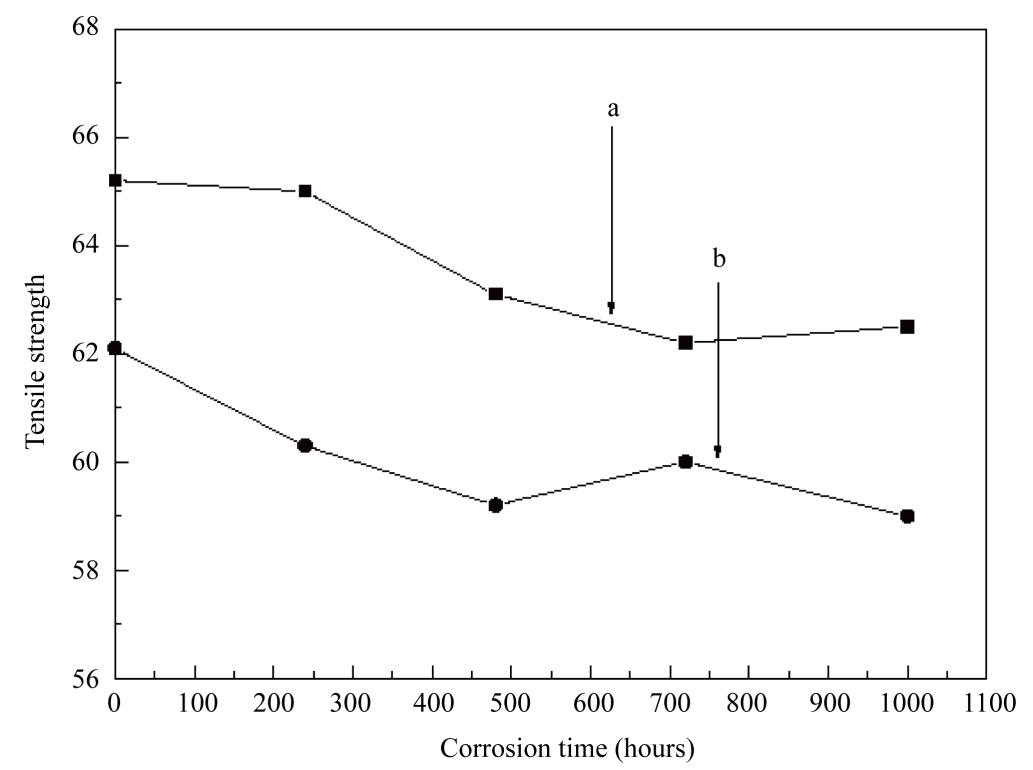

Figure 6. Evolution of tensile strengths with time in the accelerated acid corrosion test for hybrid polymer composite prepared at $25^{\circ} \mathrm{C}$ before practical use (a) and prepared at $-15^{\circ} \mathrm{C}$ after four years of use (b).

of hybrid polymer composites is very strong even after four years of use. After the corrosion test, the contact angle of hybrid polymer composites after the practical use is only $2.3^{\circ}$ lower than that of composites before use. The bonding strength of hybrid composite prepared at $-15^{\circ} \mathrm{C}$ decreases from $11.7 \mathrm{MPa}$ before the accelerated corrosion test to 9.0 MPa after. The result demonstrates that low preparation temperatures have a negative effect on the bonding strength of composites after corrosion test. After the accelerated corrosion test of 1000 hours, the tensile strength of hybrid composites before and after practical use is $62.5 \mathrm{MPa}$ and $59.0 \mathrm{MPa}$, respectively. It is concluded that the strong corrosion-resistant and mechanical properties of hybrid composite can provide the excellent protection for FGD system.

\section{References}

[1] Dou, B.L., Byun, Y.C. and Hwang, J.G. (2008) Flue Gas Desulfurization with an Electrostatic Spraying Absorber. Energy Fuels, 22, 1041-1045. http://dx.doi.org/10.1021/ef700646c

[2] Krakowiak, S., Darowicki, K. and Orlikowski, J. (2015) Assessment of Protective Properties of Rubber Lining in Absorbers of Flue Gas Desulphurization Systems. Progress in Organic Coatings, 78, 220-224. http://dx.doi.org/10.1016/j.porgcoat.2014.08.018

[3] Un, U.T., Koparal, A.S. and Öğütveren, U.B. (2007) Sulfur Dioxide Removal from Flue Gases by Electrochemical Absorption. Separation and Purification Technology, 53, 57-63. http://dx.doi.org/10.1016/j.seppur.2006.06.016

[4] Gutierrez Ortiz, F.J., Vidal, F., Ollero, P. and Salvador, L. (2006) Pilot-Plant Technical Assessment of Wet Flue Gas Desulfurization Using Limestone. Industrial \& Engineering Chemistry Research, 45, 1466-1477. http://dx.doi.org/10.1021/ie0513160

[5] Wang, Z.Y., Mei, D.S., Zhang, W.T. and Han, E.H. (2011) A Comparative Study on Several Anti-Corrosion Materials for Power FGD System. Engineering, 3, 653-658. http://dx.doi.org/10.4236/eng.2011.36078

[6] Hong, X.P., Zhu, Y. and Ma, J.Y. (2011) Electrocatalytic Oxidation of Hydroxylamine at Electro-Polymerized Poly(cobalt(II) tetraaminophthalocyanine)/Multi Walled Carbon Nanotubes Modified Electrode. Advanced Materials Research, 301-303, 1347-1350. http://dx.doi.org/10.4028/www.scientific.net/AMR.301-303.1347

[7] Feng, C., Gao, X.N., Tang, Y.T. and Zhang, Y.S. (2014) Comparative Life Cycle Environmental Assessment of Flue Gas Desulphurization Technologies in China. Journal of Cleaner Production, 68, 81-92. http://dx.doi.org/10.1016/j.jclepro.2013.10.023

[8] Saikia, D., Wu, C.G., Fang, J. and Tsai, L.D. (2014) Organic-Inorganic Hybrid Polymer Electrolytes Based on Polyether Diamine, Alkoxysilane, and Trichlorotriazine: Synthesis, Characterization, and Electrochemical Applications. Journal of Power Sources, 269, 651-660. http://dx.doi.org/10.1016/j.jpowsour.2014.06.159 
[9] Bounor-Legaré, V., Angelloz, C., Blanc, P. and Cassagnau, P. (2004) A New Route for Organic-Inorganic Hybrid Material Synthesis through Reactive Processing without Solvent. Polymer, 45, 1485-1493. http://dx.doi.org/10.1016/j.polymer.2003.12.027

[10] Mohseni, M., Bastani, S. and Jannesari, A. (2014) Influence of Silane Structure on Curing Behavior and Surface Properties of Sol-Gel Based UV-Curable Organic-Inorganic Hybrid Coatings. Progress in Organic Coatings, 77, 11911199. http://dx.doi.org/10.1016/j.porgcoat.2014.04.008

[11] Bautista, Y., Gómez, M.P., Ribes, C. and Sanz, V. (2011) Relation between the Scratch Resistance and the Chemical Structure of Organic-Inorganic Hybrid Coatings. Progress in Organic Coatings, 70, 358-364. http://dx.doi.org/10.1016/j.porgcoat.2010.09.033

[12] Yang, S., Pan, A. and He, L. (2015) Organic/Inorganic Hybrids by Linear PDMS and Caged MA-POSS for Coating. Materials Chemistry and Physics, 153, 396-404. http://dx.doi.org/10.1016/j.matchemphys.2015.01.032

[13] Wang, Z.Y., Han, E.H. and Liu, F.C. (2010) The Effect of Different Curing Agents on Cure Reaction and Exposure Resistance of Phenolic-Epoxy Resins in Hot Acid Solutions. Corrosion, 66, 1-9.

[14] Vakili, H., Ramezanzadeh, B. and Amini, R. (2015) The Corrosion Performance and Adhesion Properties of the Epoxy Coating Applied on the Steel Substrates Treated by Cerium-Based Conversion Coatings. Corrosion Science, 94, 466475. http://dx.doi.org/10.1016/j.corsci.2015.02.028

[15] Kritikos, G. (2014) Transition of the Bounded Polymer Layer to a Rigid Amorphous Phase: A Computational and DSC Study. Polymer, 55, 4658-4670. http://dx.doi.org/10.1016/j.polymer.2014.07.048

[16] Tanaka, Y., Asano, H. and Okuya, Y. (2013) Enthalpy Relaxation near the Glass Transition for Comb-Like Polymer: Power Law Relaxation Revealed by DSC Experiment. Journal of Non-Crystalline Solids, 363, 147-151. http://dx.doi.org/10.1016/j.jnoncrysol.2012.11.050

[17] Wang, K., Unger, J. and Torrey, J.D. (2014) Corrosion Resistant Polymer Derived Ceramic Composite Environmental Barrier Coatings. Journal of the European Ceramic Society, 34, 3597-3606. http://dx.doi.org/10.1016/j.jeurceramsoc.2014.05.036

[18] Mišković-Stanković, V.B., Dražić, D.M. and Kačarević-Popović, Z. (1996) The Sorption Characteristics of Epoxy Coatings Electrodeposited on Steel during Exposure to Different Corrosive Agents. Corrosion Science, 38, 1513-1523. http://dx.doi.org/10.1016/0010-938X(96)00042-X

[19] Shen, S., Cai, S., Xu, G.H. and Zhao, H.N. (2015) Influence of Heat Treatment on Bond Strength and Corrosion Resistance of Sol-Gel Derived Bioglass-Ceramic Coatings on Magnesium Alloy. Journal of the Mechanical Behavior of Biomedical Materials, 45, 166-174. http://dx.doi.org/10.1016/j.jmbbm.2015.02.005

[20] Palraj, S., Selvaraj, M., Maruthan, K. and Rajagopal, G. (2015) Corrosion and Wear Resistance Behavior of Nano-Silica Epoxy Composite Coatings. Progress in Organic Coatings, 81, 132-139. http://dx.doi.org/10.1016/j.porgcoat.2015.01.005

[21] Kalin, M. and Polajnar, M. (2014) The Wetting of Steel, DLC Coatings, Ceramics and Polymers with Oils and Water: The Importance and Correlations of Surface Energy, Surface Tension, Contact Angle and Spreading. Applied Surface Science, 293, 97-108. http://dx.doi.org/10.1016/j.apsusc.2013.12.109

[22] Kawamura, G., Ema, T., Sakamoto, H. and Wei, X. (2014) Spontaneous Changes in Contact Angle of Water and Oil on Novel Flip-Flop-Type Hydrophobic Multilayer Coatings. Applied Surface Science, 298, 142-146. http://dx.doi.org/10.1016/j.apsusc.2014.01.143

[23] Bertola, V. (2010) Effect of Polymer Additives on the Apparent Dynamic Contact Angle of Impacting Drops. Colloids and Surfaces A: Physicochemical and Engineering Aspects, 363, 135-140. http://dx.doi.org/10.1016/j.colsurfa.2010.04.031

[24] Pegoretti, A., Dorigato, A. and Brugnara, M. (2008) Contact Angle Measurements as a Tool to Investigate the FillerMatrix Interactions in Polyurethane-Clay Nanocomposites from Blocked Prepolymer. European Polymer Journal, 44, 1662-1672. http://dx.doi.org/10.1016/j.eurpolymj.2008.04.011

[25] Lee, C.Y., Bae, J.H. and Kim, T.Y. (2015) Using Silane-Functionalized Graphene Oxides for Enhancing the Interfacial Bonding Strength of Carbon/Epoxy Composites. Composites Part A: Applied Science and Manufacturing, 75, 11-17. http://dx.doi.org/10.1016/j.compositesa.2015.04.013

[26] Frese, C., Decker, C. and Rebholz, J. (2014) Original and Repair Bond Strength of Fiber-Reinforced Composites in Vitro. Dental Materials, 30, 456-462. http://dx.doi.org/10.1016/j.dental.2014.01.010

[27] Jarray, A., Gerbaud, V., and Hémati, M. (2015) Prediction of Solid-Binder Affinity in Dry and Aqueous Systems: Work of Adhesion Approach vs. Ideal Tensile Strength Approach. Powder Technology, 271, 61-75. http://dx.doi.org/10.1016/j.powtec.2014.11.004

[28] Mortazavian, S. and Fatemi, A. (2015) Effects of Fiber Orientation and Anisotropy on Tensile Strength and Elastic Modulus of Short Fiber Reinforced Polymer Composites. Composites Part B: Engineering, 72, 116-129.

http://dx.doi.org/10.1016/j.compositesb.2014.11.041 